\title{
Towards an evidence-based approach for road mitigation schemes for amphibians and reptiles in the U.K. - a review
}

\author{
S.O. Petrovan ${ }^{1,2}$ \\ ${ }^{1}$ Conservation Science Group, Department of Zoology, The David Attenborough Building, University of \\ Cambridge, Cambridge CB2 3QZ \\ 2Froglife, 1 Loxley, Werrington, Peterborough PE4 5BW \\ E-mail: sop21@cam.ac.uk
}

\begin{abstract}
Road networks have substantial and diverse impacts on wildlife, including amphibians and reptiles. However, despite significant progress, ecological mitigation measures designed to reduce such impacts are often insufficiently tested and described in terms of their efficiency for a range of species. Incorporating a solid evidence-based approach could greatly benefit the sector as a whole, but would require increased and adequate monitoring effort of implemented mitigation schemes, as well as a requirement to make the results available, to ensure practitioners use and regulators validate the evidence. To this goal The Conservation Evidence project (www.conservationevidence.com) brings together and evaluates conservation actions to make them freely accessible and directly comparable for practitioners.
\end{abstract}

\section{REVIEW}

Roads and road traffic have been known to represent threats to wildlife and habitats for almost 100 years (Forman, 1998; Van der Ree et al., 2011), but proactive measures to reduce such impacts, broadly known as ecological road mitigation measures, have become widely adopted only in recent decades. At the same time, the study of the impacts of transport infrastructure and traffic on the wider environment including wildlife and habitats, now referred to as "Road ecology", has become a fully-fledged branch of ecological research, with rapidly growing numbers of targeted scientific papers, books, conferences (e.g. IENE in Europe www.iene.info/, or ICOET in North America www.icoet.net/ICOET_2019/index.asp), and best practice guidelines.

Huge progress has been achieved in understanding and documenting the extensive ecological effects of road networks (Coffin, 2007). These effects range from barriers to movement and enormous sources of wildlife-traffic collisions, to acting as dispersal corridors, including for invasive species. Roads also play a role in promoting habitat loss and land use changes (e.g. from forest to agricultural land), and in causing alterations to the hydrology, sedimentation rates, water and air chemistry, as well as substantial sound and light pollution. Each of these factors can potentially transform the fate of local wildlife populations; additionally they typically act together. As such, the task of reducing or mitigating such factors is daunting and inherently complex.

For many of the road-associated ecological effects mitigation measures, guidelines and options designed to minimize impact have been published, such as those described in the COST 341 handbook (Trocmé et al., 2003). These guidelines start from the planning stage (e.g. via avoidance of road construction in ecologically valuable habitat, proposing mitigation schemes etc.), to the construction stage, both for the impact during construction as well as including specific infrastructure (e.g. wildlife passages, attenuation ponds to collect water runoff, noise-absorbent panels, modified spectrum streetlights etc.). Postconstruction, there are numerous other measures aimed at reducing negative impacts on the environment, from using less polluting fuels, to traffic speed reductions in particular road sectors, and automated systems for detecting the presence of wildlife near roads and alerting the drivers via traffic warnings.

Greater understanding of road mitigation measures has allowed landscape scale planning of green corridors, combining habitat creation and restoration with underpasses or overpasses in a way which would have been impossible 20-30 years ago (Langton, 2015). Yet numerous challenges and questions of mitigation effectiveness remain, perhaps unsurprisingly given the complexity of the task.

There have been well-publicised cases of mitigation failure and "evidence complacency" perhaps most notably shown in the case of road mitigation measures for bats. Here bat gantries designed to provide a safe passage for bats over the roads have continued to be implemented even after they were shown to be ineffective (Berthinussen \& Altringham, 
2012; Sutherland \& Wordley, 2017). Conservation practitioners or consultant ecologists often do not have the time or access to consult scientific literature, mitigation monitoring results generally remain hidden in reports, and a substantial amount of conservation actions remains untested.

However, financial resources for conservation measures are scarce and numerous species are rapidly declining, including in the U.K. Thus it is vital for implemented mitigation projects to fulfill their roles. For road mitigation, this is especially relevant given the seemingly inexorable demand for road construction and increases in traffic volumes.

In the U.K., which has one of the densest road networks in the world, traffic volumes and the numbers of vehicles have almost doubled over the past 35-40 years, and new road construction projects inherently clash with the need to protect remnant fragments of habitat (Department for Transport, 2014). Construction sites across southeast England are a visible testament to this, with miles of "newt fencing" designed to prevent accidental killing or injuring of the protected great crested newt (Triturus cristatus) during road building and road widening projects.

While many aspects of road mitigation for species such as deer (Cervidae) or large carnivores are now well studied and robustly implemented, there is a general lack of targeted evidence-based support for road mitigation for a wide range of other vertebrates including smaller mammals, reptiles and amphibians (Lesbarreres \& Fahrig, 2012; Beebee, 2013). This is despite the fact that there is growing awareness that roads are severely affecting such species, most likely contributing to their declines such as those apparent in two widespread and previously common species, the common toad (Bufo bufo) and the European hedgehog (Erinaceus europaeus) (Huijser \& Bergers, 2000; Petrovan \& Schmidt, 2016).

The great crested newt provides an example of the lack of mitigation implementation analysis. Despite numerous projects that have incorporated road mitigation measures for this species since the 1990s, the first scientific paper describing the usage by newts of one such road mitigation was published only in 2017 (Matos et al., 2017). This study indicated that the mitigation measures were used differently by newts compared with other amphibian species, as most newt road crossing through tunnels took place during late autumn-winter and not the spring (Fig. 1).

Such findings are important as they demonstrate that mitigation measures should be tailored for the species ecology rather than for broad groups (e.g. amphibians), and that once implemented they need careful monitoring to evaluate their usage and effectiveness. Implementing road tunnels for newts in a typical amphibian scenario, by connecting terrestrial and aquatic habitat using tunnels and fences, instead of connecting areas with breeding ponds on both sides of the road, could be damaging for populations, as encouraging dispersal movements into areas with no breeding habitat could result in newts being stranded.

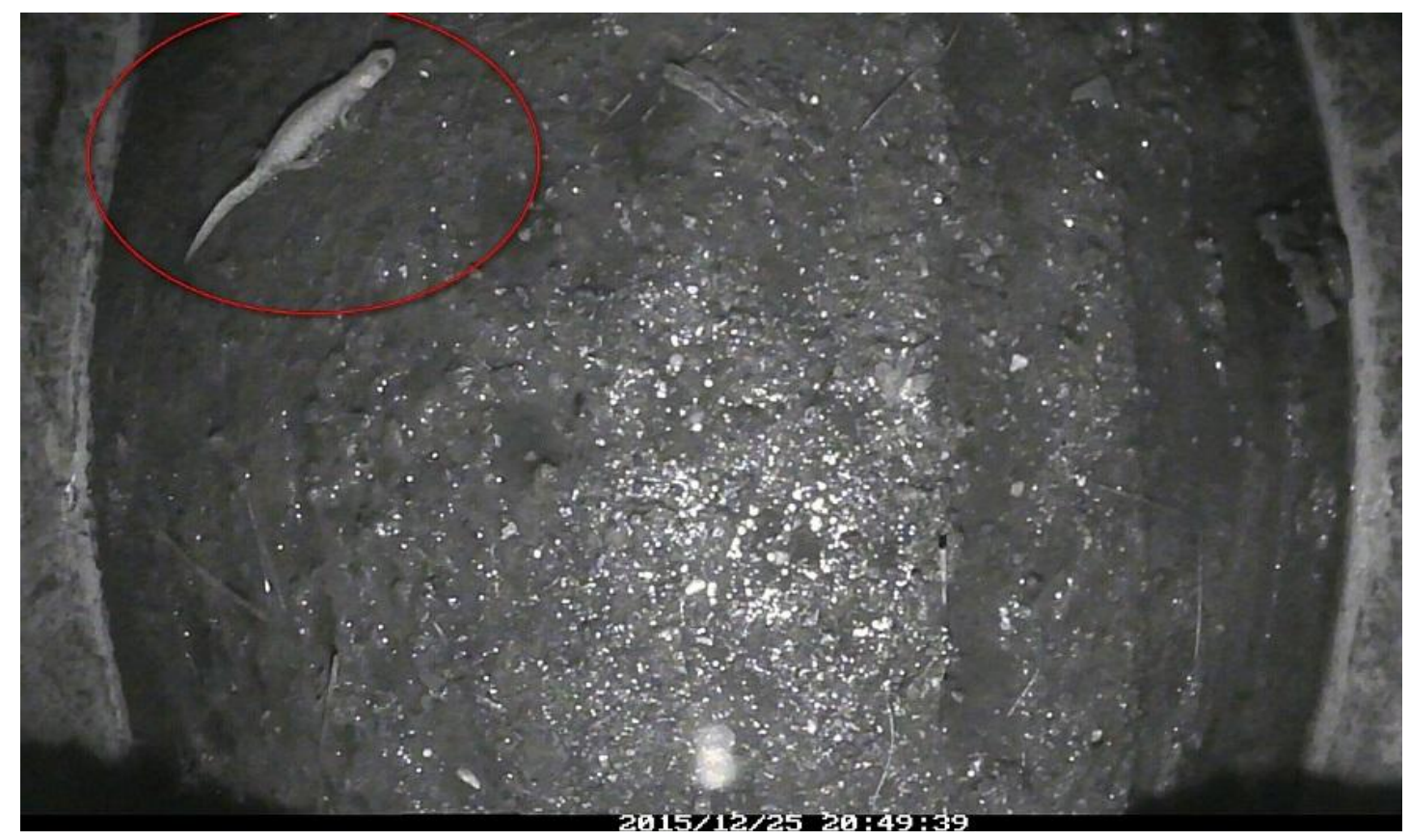

Fig. 1. Female great crested newt (Triturus cristatus) crossing an ACO amphibian road tunnel in England as recorded by Froglife custom-made cameras. Note the date of 25th December 2015. Collecting information using novel technology allows data gathering over long periods and can reveal interesting species ecology. In this case, the mild winter weather in 2015/16 meant that newts continued to be active throughout the winter months. (Photo: Froglife) 
Evidence-based evaluations, such as the Cochrane Collaboration (http://www.cochrane.org) operate by bringing together and reviewing the evidence on scientific trials of medical treatments. The Conservation Evidence project (www.conservationevidence.com) has a similar purpose applied to conservation, through collating and synthesizing information on the success of conservation interventions, ultimately for all species groups and habitats. It provides a free, authoritative and user-friendly resource aiming to facilitate effective decision-making by conservation practitioners and policy makers.

While Reptile Conservation and Mammal Conservation are currently in preparation, the Amphibian Conservation synopsis was published and has been evaluated by a group of experts from across the globe (Smith et al., 2018). What can it teach us about road mitigation for amphibians? One example is the evaluation of volunteers used to move amphibians across the road, known in the U.K. as "Toads on Roads". Rather worryingly it was found to be "Unlikely to be beneficial". While this might dismay the extremely dedicated volunteers that go out night after night and move amphibians to protect them from cars, a recent analysis of the 30-year data collected in the U.K. and Switzerland showed that substantial toad declines have continued even in sites with toad patrols (Petrovan \& Schmidt, 2016). The work from volunteers, while invaluable as citizen science to estimate long-term trends, appears unable on its own to halt population declines. However, more positively, the volunteer work is likely to be significantly slowing the rate of declines, and thus allowing more time to search for additional solutions.

In contrast, the effectiveness of "Install culverts or tunnels as road crossings" is relatively well supported in the Amphibian Conservation synopsis, with 32 studies. But even here, there is evidence that some designs are not effective, or that high levels of mortality continued at some sites (Smith $e t$ al., 2018). As mentioned, at the time of data collection in 2014, there were no studies on great crested newts. Additionally, almost no studies addressed the usage of such tunnels or underpasses by juveniles, instead focusing on adult migrations in spring to the breeding areas.

The effectiveness of road signs warning motorists to protect amphibians appeared to be poorly supported by evidence. However, the main reason why many volunteers install traffic warning signs is not to protect amphibians but rather to indicate to motorists that volunteers are on roads rescuing toads, and thus to be vigilant and drive slowly. Installing barrier fencing along roads was much better supported, but the outcome was assessed as "Trade-off between benefit and harms". Effective fencing can rapidly reduce mortality and thus eliminate the obvious issue on mass mortalities on the roads. Even so, unless they are combined with effective tunnels, the whole system acts as a barrier and can result in a substantial reduction in breeding activity, lack of recruitment and ultimately the extinction of populations.

\section{CONCLUSIONS}

Considering the large volume of literature included as part of the Amphibian Conservation synopsis, with 49 systematically searched journals (https://www.conservationevidence.com/journals earcher/index), the evidence remains limited for a range of important conservation actions, including road mitigation, highlighting the need for targeted research. A participative effort, with conservation practitioners examining, testing and publishing the evidence of effectiven ess of success is an important step in improving the outlook for a range of conservation actions, and has the potential to create a fundamental change in the way to do conservation. Though road mitigation is often expensive, it is directly relevant and important for the conservation of wildlife, including smaller vertebrates, and so it is vital that it is correctly implemented. Strategic research, participative monitoring efforts and publication of the results could substantially improve the current situation.

\section{ACKNOWLEDGEMENTS}

At the University of Cambridge SOP is generously supported by Arcadia. At Froglife SOP was supported by the Esmee Fairbairn Foundation, Natural England, the British Ecological Society, and People's Trust for Endangered Species.

\section{REFERENCES}

Beebee, T.J. (2013). Effects of road mortality and mitigation measures on amphibian populations. Conservation Biology 27, 657-668.

Berthinussen, A. \& Altringham, J. (2012). Do bat gantries and underpasses help bats cross roads safely? PLOS ONE 7, e38775. https://doi.org/10.1371/journal.pone.0038775

Coffin, A.W. (2007). From roadkill to road ecology: a review of the ecological effects of roads. Journal of Transport Geography 15, 396-406.

Department for Transport (2014). Vehicle Licensing Statistics 2013. Statistical release 10 April 2014. National Statistics.

https://www.gov.uk/government/statistics/veh icle-licensing-statistics-2013

Forman, R.T. (1998). Road ecology: a solution for the giant embracing us. Landscape Ecology 13, III-V.

Huijser, M.P. \& Bergers, P.J. (2000). The effect of roads and traffic on hedgehog (Erinaceus europaeus) Conservation 95, 111-116.

Langton, T.E. (2015). A history of small animal road ecology. In: Riley S.P.D., Nanjappa, P. \& Andrews, 
K.M. (Editors). Roads and Ecological Infrastructure: Concepts and Applications for Small Animals, pp 7-19. Johns Hopkins University Press, Baltimore, U.S.A.

Lesbarreres, D., \& Fahrig, L. (2012). Measures to reduce population fragmentation by roads: what has worked and how do we know? Trends in Ecology \& Evolution 27, 374-380.

Matos, C., Petrovan, S., Ward, A.I. \& Wheeler, P. (2017). Facilitating permeability of landscapes impacted by roads for protected amphibians: patterns of movement for the great crested newt. PEERJ 5, e2922.

Petrovan, S.O. \& Schmidt, B.R. (2016). Volunteer conservation action data reveals large-scale and long-term negative population trends of a widespread amphibian, the common toad (Bufo bufo). PLoS ONE 11, e0161943. https://doi.org/10.1371/journal.pone.0161943

Smith, R.K., Meredith, H. \& Sutherland, W.J. (2018) Amphibian conservation. In: Sutherland, W.J., Dicks, L.V., Ockendon, N., Petrovan, S.O. \& Smith R.K. (Editors). What Works in Conservation 2018, pp. 9-65. Open Book Publishers, Cambridge.

Sutherland, W.J. \& Wordley, C.F. (2017). Evidence complacency hampers conservation. Nature Ecology \& Evolution 1, 1215.

Trocmé, M., Cahill, S., De Vries, J.G., Farrall, H., Folkeson, L., Fry, G. et al. (2003). COST 341 Habitat Fragmentation due to Transportation Infrastructure: the European Review, pp. 3150. Office for official publications of the European Communities, Luxembourg,

Van der Ree, R., Jaeger, J.A., Van der Grift, E.A. \& Clevenger, A.P. (2011). Effects of roads and traffic on wildlife populations and landscape function: road ecology is moving toward larger scales. Ecology and Society 16, 48. 